\title{
AS CONTRATAÇÕES EMPRESARIAIS: UMA VISÃO ACERCA DOS MECANISMOS IMPULSIONADORES À EFETIVAÇÃO DA DIGNIDADE HUMANA E PROMOÇÃO DA RESPONSABILIDADE SOCIAL
}

\section{BUSINESS CONTRACTING: A VISION ABOUT THE IMPULSING MECHANISMS FOR EFFECTIVENESS OF HUMAN DIGNITY AND PROMOTION OF SOCIAL RESPONSIBILITY}

André Lipp Pinto Basto Lupi ${ }^{1}$

Silvana Fátima Mezaroba Bonsere ${ }^{2}$

\section{RESUMO}

O presente estudo busca compreender quais os mecanismos impulsionadores de due diligence nas contratações empresariais no Brasil, vislumbrando se tocam aspectos da dignidade da pessoa humana e da promoção da responsabilidade social empresarial. Adotou-se a metodologia de pesquisa bibliográfica, com uma investigação histórica acerca do tema proposto, publicações no mercado nacional e internacional, bem como a pesquisa documental acerca de recentes julgados envolvendo o processo de diligência prévia no Brasil. Como resultado do presente estudo, que perpassa por uma definição teórica e origem histórica da due diligence, pela relevância deste processo nas contratações empresariais com vistas à efetivação da dignidade da pessoa humana e promoção da responsabilidade social empresarial, e finalmente especifica os mecanismos nacionais que impulsionam esta análise diligente, concluiu-se que o Brasil possui mecanismos eficazes para a concreta realização de um processo de due diligence, com vistas à efetivação da dignidade humana e promoção da responsabilidade social, e basta o Estado naquilo que lhe cabe, e o particular em cada contratação, exigir dos stakeholders a adoção desta postura de análise mínima destes mecanismos. As contribuições trazidas conferem maior visibilidade a estes instrumentos de fácil acesso de consulta por qualquer cidadão, empresa e poder público, que a propósito, concorrem para efetivação da dignidade humana e promoção da responsabilidade social empresarial.

Palavras-chave: Due diligence; dignidade humana; responsabilidade social; trabalho escravo; contratos.

\section{ABSTRACT}

\footnotetext{
${ }^{1}$ Professor do Programa de Mestrado e Doutorado do UNICURITIBA.

${ }^{2}$ Acadêmica do Curso de Mestrado - Centro Universitário Curitiba - UNICURITIBA. Curitiba - PR. E-mail: silvanamezaroba@gmail.com.
} 
This study seeks to understand the mechanisms that drive due diligence in business in Brazil, to visualize if they touch aspects of human dignity and promotion of corporate social responsibility. The bibliographic research methodology was adopted, with a historical investigation about the proposed theme, publications in the national and international market, as well as documentary research about recent judgments involving the process of prior due diligence in Brazil. As a result of the present study, which goes through a theoretical definition and historical origin of due diligence, due to the relevance of this process in business hiring with a view to realizing the dignity of the human person and promoting corporate social responsibility, and finally specifying the national mechanisms that drive this diligent analysis, it was concluded that Brazil has effective mechanisms for the concrete realization of a due diligence process, with a view to the realization of human dignity and promotion of social responsibility, and the State is sufficient in what it is responsible, and the private in particular each contract, require the stakeholders to adopt this post of minimum analysis of these mechanisms. The contributions brought make these instruments easily accessible for consultation by any citizen, company and public authority, which, by the way, contribute to the realization of human dignity and the promotion of corporate social responsibility.

Key-words: Due diligence; human dignity; social responsibility; slavery; contracts.

\section{INTRODUÇÃO}

A due diligence nas contratações empresariais já é algo largamente aplicado, principalmente em grandes empreendimentos e com vistas a observância de eventuais riscos que possam comprometer, encarecer ou até mesmo exigir novas cláusulas contratuais nas negociações empresariais. Inicialmente o processo de devida diligência surge como uma forma de conhecer os envolvidos na relação e terceiros, bem como para melhor gerir os negócios praticados.

Ocorre, no entanto, que a medida em que a sociedade evolui, as práticas de gestão e responsabilização também, e por isso, faz-se necessário compreender quais os mecanismos impulsionadores de um processo de due diligence nas contratações empresariais no Brasil, e verificar se possuem relação com os anseios de efetivação da dignidade humana e promoção da responsabilidade social.

Primeiramente pode-se dizer que para alcançar um olhar mais estratégico do futuro, mas também porque o processo de due diligence passa a ser um forte aliado das organizações para realização de negociações sustentáveis e duradouras, alcançando reputação nacional e internacional à organização. Da mesma forma, ao se transcender os aspectos econômicos, os negócios passam a adotar uma atitude positiva perante a sociedade como um todo, e dessa forma contribuem para o desenvolvimento nacional, que é um dos objetivos fundamentais da República, previsto no artigo 3º, II da Constituição Federal de 1988. 
A partir da compreensão dos mecanismos impulsionadores ao processo de devida diligência no Brasil, espera-se conferir maior visibilidade a estes instrumentos de fácil acesso de consulta por qualquer cidadão, organização e poder público, e que contribuem para efetivação da dignidade humana e promoção da responsabilidade social empresarial.

Para tanto, a metodologia utilizada foi a pesquisa bibliográfica com uma investigação histórica acerca do tema proposto, publicações no mercado nacional e internacional, bem como a pesquisa documental acerca de recentes julgados envolvendo o processo de diligência prévia no Brasil.

Inicia-se pela definição teórica e origem histórica da due diligence, para depois introduzir-se relevância deste processo nas contratações empresariais com vistas à efetivação da dignidade da pessoa humana e promoção da responsabilidade social empresarial, para finalmente compreender-se quais os mecanismos nacionais que impulsionam esta análise diligente nas contratações empresariais e ainda, funcionam como instrumentos de transformação social.

Acrescente-se que o presente estudo não esgota todos os mecanismos impulsionadores de um processo de due diligence na esfera das contratações empresariais, mas buscou trazer aqueles mais relevantes no atual cenário político-econômico e que por sua vez, colaboram mesmo que indiretamente para a efetivação da dignidade da pessoa humana e promoção da responsabilidade social.

\section{DUE DILIGENCE: DEFINIÇÃO TEÓRICA E ORIGEM HISTÓRICA}

Indiscutivelmente, as pessoas contratam dos mais variados modos e sob os mais diversos interesses ou necessidades. A doutrina explica que os contratos ocupam um lugar de destaque entre os negócios jurídicos, e é por meio deles que as pessoas acertam suas intenções e interesses, constituindo, modificando ou até mesmo extinguindo direitos. (RIZZARDO, 2014, p. 3). Assim também é o que ocorre no universo empresarial: empresas celebram contratos cotidianamente desde negócios mais simples aos mais complexos.

Com base neste aspecto e objetivando antever situações que possam representar algum risco a determinado contrato ou negociação é que surge a due diligence, descrita por anglosaxão dividido em duas expressões $(d u e=$ devida; diligence $=$ diligência $)$ tem-se a tradução para "devida diligência", ou também "devida cautela", o que expede um dever de cuidado, de análise prévia. (BATALHA, 2016, p. 56). 
De origem histórica no preceito romano diligentia quam suis rebus, que tinha o significado de "diligência de um cidadão em gerenciar suas coisas" (PANOSSO, 2013, p. 21), o due diligence, hoje assim disseminado possuía uma conotação inicial de que o comerciante da época deveria tomar atitudes diligentes prévias, porque se fosse o caso, poderia atestar a sua conduta prudente como meio de defesa num conflito judicial. (ROCHA, 2012, p. 51).

Ocorre, no entanto, que com a promulgação da Securities Exchange Act ${ }^{3}$ no ano de 1934 nos Estados Unidos da América $^{4}$, a due diligence surge como uma forma de conhecer a outra parte da relação, também como mecanismo de defesa diante dos terceiros, eis que "aqueles que ofertassem a compra de ações no mercado de capitais seriam responsabilizados pela inexatidão ou falsidade nas informações que prestassem”. (ROCHA, 2012, p. 51-52). Muito depois, em 2002, também nos Estados Unidos, tem-se a publicação de uma nova legislação Lex Sarbanes-Oxley - que prevê o dever das companhias prestarem informações periódicas sob pena de responsabilização dos dirigentes. (ROCHA, 2012, p. 52).

No Brasil, o Instituto Brasileiro de Governança Corporativa (IBGC) publicou em 1999 a primeira versão do seu Código de Melhores Práticas de Governança Corporativa (1999, p. 12), no qual já previa o direito dos acionistas e do mercado a informações verídicas, equilibradas, transparentes e oportunas. Em 2000, a Bolsa de Valores de São Paulo (BOVESPA), visando justamente aumentar os níveis de transparência e garantir o aperfeiçoamento das normas de governança corporativa, bem como, incentivar os investimentos dos mercados de capitais, criou segmentos especiais chamados "Níveis Diferenciados de Governança Corporativa", (GUSMÃO, 2015, p. 481), dentre eles o Nível 1, Nível 2, e Novo Mercado, que exigem práticas adicionais às previstas na legislação. (ARRUDA, 2017, p. 61).

A partir de então, a Lei 10.303 de 31 de outubro de 2001, que alterou a Lei das Sociedades Anônimas, também trouxe algumas modificações para a transparência no mercado de capitais no Brasil, que para a professora Mônica Gusmão (2015, p. 480), significa trazer à cena a governança corporativa, com mecanismos para a sua aplicação. E, em 2002, a Comissão de Valores Mobiliários (CVM) edita a sua Cartilha de Governança Corporativa fazendo menção ao princípio da transparência. (ALVES; HARET; SILVEIRA, 2015, p. 340).

Note-se que a evolução legislativa no Brasil trata reiteradamente da transparência voltada para o mercado, com o intuito de gerar confiança em quem está investindo. A due

\footnotetext{
${ }^{3}$ Lei do Mercado de Valores Mobiliários (tradução livre).

${ }^{4}$ Período exatamente após a depressão dos Estados Unidos em razão da quebra da Bolsa de Valores de Nova York.
} 
diligenge foi preconizado pela prática norte-americana, revelou-se no mercado brasileiro em razão da Bolsa de Valores de São Paulo, mais precisamente com a instituição do Novo Mercado (ROCHA, 2012, p. 53), mas a governança corporativa também regula o dever de cuidado e de diligência. (LOBO, 2007, p. 199).

Importante destacar que não haverá um conceito único acerca de due diligence, mas de forma objetiva foi definido por Londoño $(2008$, p. 263) como "um processo de coleta ou levantamento de informação cuja principal função é a análise da possibilidade para realizar algum tipo de negócio". Fazendo-se uma análise mais abrangente due diligence pode ser visto também como um procedimento prévio de análise de dados e informações de outra parte relacionada, quando há interesse na firmatura de um negócio, com o objetivo de avaliar viabilidade econômica, riscos de perda ou contingenciamento financeiro, e até mesmo riscos de responsabilização conexa ou dano extrapatrimonial. (ROCHA, 2012, p. 60). Trata-se de conhecer o negócio para melhor dimensionar os seus riscos e oportunidades, em aspectos que extrapolam o mero caráter mercadológico e avançam em aspectos estruturais, contábeis e jurídicos.

No Mercado de Fusões e Aquisições (F\&A) a due diligence tem papel fundamental, em razão de que estas operações são mecanismos importantes para que as organizações alcancem crescimento. Assim, o processo de due diligence se torna um mecanismo indispensável, de natureza multidisciplinar, que abrange a análise de todos os aspectos do negócio e se ocupa de diversas páreas de conhecimento, senão veja-se:

Due diligence cobre uma variedade de áreas. Idealmente, uma due diligence completamente conduzida considera todos os aspectos do negócio alvo. Estas áreas incluem, mas não estão limitadas à, legal, contabilidade, tributação, tecnologia da informação, risco e seguro, meio ambiente, presença no mercado e vendas, operações, propriedade real e pessoal, ativos intelectuais e intangíveis, finanças, questões transfronteiriças, organização e recursos humanos, cultura e ética. (BAM, W.G.; BHAGWAN, V.; GROBBELAAR, S.S., 2018, p. 223, tradução livre).

BLOK (2014, p. 105) por sua vez define a due diligence nos seguintes termos:

O processo de due diligence envolve basicamente a coleta de informações a fim de realizar levantamentos e análises detalhadas acerca da atual situação do negócio a ser adquirido. Quanto maior a quantidade de informações e de detalhes obtidos, mais precisos serão os subsídios dos elementos para realização de projeções de natureza financeira, econômica, jurídica e estratégica quanto ao futuro do negócio adquirido após o fechamento da operação. 
Nos processos de fusões e aquisições de empresas, normalmente há um forte trabalho de diligência prévia para apuração do patrimônio da empresa que será adquirida através da análise dos mais variados relatórios contábeis. (RAUPP; WARKEN, 2009, p. 33). São analisados passivos e ativos, em profundidade, para dimensionar adequadamente a confiabilidade da escrituração contábil e sua representatividade de realidade econômica. De outra banda, procura-se identificar valores resgatáveis ou que poderiam decorrer de sinergias do negócio.

Isso se justifica pois no período que antecede a aquisição os investidores desejam conhecer a situação atual da empresa, bem como projeções, dentre outras variáveis que poderão determinar a viabilidade do negócio, seu sucesso ou fracasso. No entanto, o processo de due diligence pode ser utilizado também como um mecanismo para determinar o estado de uma empresa, antes mesmo de uma possível integração, com o objetivo de antecipar alguns riscos que possam afetar o seu valor. (DUEÑAS, 2014, p. 5). E, conhecendo o negócio será possível firmar contratos garantidos com retenção de pagamento, por exemplo, o que evita um processo de execução em caso de surgimento de uma contingência oculta, ou perda econômica. (DUEÑAS, 2014, p. 17).

Não se pode olvidar também, que as averiguações em processos de fusões e aquisições são realizadas com o objetivo de obtenção de informações que possam afetar o futuro, como por exemplo, o valor econômico de uma empresa. Trata-se a due diligenge, portanto, como um processo gerencial estratégico, que permite ao comprador ter acesso a informações que poderão colocá-lo em posição mais vantajosa em termos negociais. Por isso, se diz que o processo é multidisciplinar, com diversos níveis de profundidade, cujo objetivo por vezes, é tomar conhecimento de informações que não sejam de domínio público. (RAUPP; WARKEN, 2009, p. 33).

O Superior Tribunal de Justiça (STJ), em decisão envolvendo incorporação societária, reafirmou que esta espécie de negócio pressupõe um processo de due diligence para avaliação dos efeitos da transação. E ainda, enalteceu que a diligência prévia nestes casos envolve ampla investigação acerca de aspectos "societários, financeiros, fiscais, contábeis, trabalhistas, previdenciários, administrativos, comerciais e produtivos" que possam estar envolvidos, por conta da reorganização da empresa. (STJ, REsp 1789554/SP, 2019).

Os exemplos mais clássicos da literatura que são a utilização da diligência prévia ou devida cautela nos processos de Fusões e Aquisições, Joint Venture, Investidor-Anjo (BARBERO et al., 2016, p. 350), explicam que due diligence não é um instituto jurídico autônomo, com um conjunto de regras e normas, mas "deve estar vinculada à estratégia 
corporativa do investidor". (ROSENBLOOM, 2002, p. 3). Trata-se de um processo que segue um procedimento de pesquisa viabilizando a análise de uma entidade ou negócio dentro de um escopo predeterminado. (ALVAREZ et al., 2011, p. 213). Seu escopo é definido em razão das necessidades do negócio e da estratégia dos interessados na due diligence.

Difere-se, portanto, da auditoria, já que esta tem foco no passado e o nível de alcance normalmente é definido por uma regulamentação, o acesso não é restringido, a verificação se dá com base em testes substantivos, e o parecer em formato regulamentado limitado; e, por sua vez, o processo de due diligence guarda foco no passado, presente e futuro, o seu alcance é definido pelas partes interessadas (clientes), o acesso poderá ser restringido, a verificação é limitada, e o parecer revela a história completa. (LONDOÑO, 2008, p. 268). Por seu turno, a finalidade da due diligence, é identificar e gerir riscos, que poderão ser fiscais/tributários, trabalhistas, ambientais, financeiros, dentre outros, e ainda, compreender do funcionamento e gestão de uma empresa, com o objetivo de formar preço, confirmar a rentabilidade do negócio, identificar pontos fortes e pontos fracos de gestão administrativa financeira, contar patrimônio, ou até mesmo, se for o caso, avaliar a compatibilidade de filosofia e conhecer ambientes. (RAUPP; WARKEN, 2009, p. 36).

Assim, é importante destacar que os processos de due diligence poderão ser classificados em alguns tipos, ou formas, a depender do objetivo do negócio ou contrato que vier a ser firmado. Para Rosa (2012, p. 61) o processo de due diligence poderá estar voltado para o mercado de capitais, quando são analisadas informações para oferta de ações neste mercado, para o mercado financeiro, quando se analisa a saúde financeira de uma empresa, e por fim, para as operações societárias, com a finalidade de avaliar a empresa como um todo, identificando riscos e mitigando-os. Ainda, por se tratar de um processo multidisciplinar, poderá haver a separação dos trabalhos por equipes de profissionais especializados, e dentre estes, os profissionais jurídicos, financeiros e de operações. (DUEÑAS, 2014, p. 7).

Todavia, o processo poderá também ser mais estratificado, e por isso, aprofundar-se nas seguintes áreas: (i) due diligence financeira, que analisa os valores de ativos e passivos, toda a estrutura e saúde financeira, balanços e projetivos, e, normalmente, o seu objetivo é revisar informação comercial e financeira, bem como estrutura de capital para base da formação de preço adequado; (ii) due diligence fiscal, que analisa a situação tributária, previdenciária, passivo nesta seara, e o objetivo principal é tomar cuidados com questões tributárias que poderão não chegar a conhecimento, ou então prevenir um futuro passivo (BATALHA, 2016, p. 70-72); (iii) due diligence societária, que analisa os atos societários, procurações, acordos societários, quaisquer documentos que impliquem a emissão de valores mobiliários, dentre 
outros documentos, visando compreender a estrutura jurídico-societária e buscando focar em assuntos que poderão se tornar possíveis impedimentos para uma negociação (ROCHA, 2012, p. 63); (iv) due diligence laboral ou trabalhista, que visa analisar toda a questão de colaboradores, convenções coletivas de trabalho, contratos, seguros sociais, clima organizacional, dentre outros aspectos que envolvem as relações de trabalho, buscando mensurar contingências trabalhistas; (v) due diligence ambiental, com vistas a identificar problemas ambientais e possíveis responsabilidades em razão de não cumprimento de leis ambientais, busca-se diligenciar efetivamente na averiguação de possíveis passivos ambientais; (vi) due diligence operativa que avalia o mercado, as condições de operação, os concorrentes, dentre outros fatores que objetivam conhecer a viabilidade do negócio ou de determinada operação; (vii) due diligence circunstancial cujo objetivo é verificar se há risco de assunção de novos passivos em razão da mudança frequente de legislação, visando antever onerações de determinada operação e/ou negócio. (BATALHA, 2016, p. 72-74).

Embora o processo de due diligence seja amplamente utilizado para negócios vultuosos, como por exemplo, Fusões e Aquisições, poderá ser aplicado também para contratos empresariais mais modestos, a saber que a sua significância está em prevenir riscos trabalhistas, tributários, ambientais, éticos, financeiros, de imagem, dentre tantos outros que poderão ser agregados conforme o negócio que esteja sendo analisado ou realizado, o que por sinal é o objetivo deste estudo.

Assim, a devida diligência contratual se mostra como um olhar para o passado na busca de informações pretéritas, mas ao mesmo tempo como um olhar muito estratégico de futuro, porque "Aqueles que ignoram o passado estão condenados a repeti-lo", mas "Aqueles que não querem olhar para o futuro podem pagar um preço semelhante" (LONDOÑO, 2008, p. 278, tradução livre), e nas contratações empresarias corriqueiras, o processo de due diligence pode ser um forte aliado das organizações para realização de negociações sustentáveis, mais duradouras, mostrando-se também como "um dos pilares do programa de Compliance" (KUZNECOV, 2017, p. 26). De fato, uma empresa que preza por padrões adequados de compliance haverá sempre de empreender uma due diligence em seus negócios de maior relevo estratégico.

\section{RELEVÂNCIA DA DEVIDA DILIGÊNCIA NAS CONTRATAÇÕES EMPRESARIAIS PARA EFETIVAÇÃO DA DIGNIDADE DA PESSOA HUMANA E PROMOÇÃO DA RESPONSABILIDADE SOCIAL EMPRESARIAL}


Explorar a relevância da devida diligência nas contratações empresariais com vistas à efetivação da dignidade da pessoa humana e promoção da responsabilidade social empresarial, implica, inicialmente, numa breve compreensão daquilo que deve ser levado em consideração nas negociações contratuais para garantir este fundamento da República Federativa do Brasil, e, depois, entender qual a adequada prática de gestão dos negócios.

Ao se adentrar para a efetivação da dignidade da pessoa humana, cumpre destacar que é um dos fundamentos que alicerçam o Estado Democrático de Direito, traçando às pessoas um valor intrínseco absoluto, ou seja, "princípio que unifica e centraliza todo o sistema normativo, assumindo especial prioridade" (PIOVESAN, 2018, p. 107-109). Aliás, dentro da estrutura constitucional, a dignidade humana exerce a função de "fonte jurídico-positiva de direitos fundamentais", sendo estes a materialização da dignidade humana, isto é, quando os direitos fundamentais individuais, coletivos, sociais ou direitos políticos são alcançados na sua plenitude, houve então a concreção da dignidade humana. (SILVA; MASSON, 2015, p. 191). Por estas razões, a dignidade da pessoa humana, não pode ser olvidada nas relações contratuais empresariais, merecendo guarida especial num processo de due diligence.

Por conseguinte, há que se perguntar quando a dignidade da pessoa humana restará preservada numa relação contratual empresarial? É neste ponto que o processo de due diligence se mostra adequado para que sejam observadas algumas premissas mínimas antes de firmar qualquer negócio, ou seja, trata-se de uma análise que vai além da capacidade econômica, mas que exige uma postura adequada inclusive dos quarteirizados, e impõe ao contratado e contratante uma atitude positiva diante daquilo que está consagrado no texto constitucional os direitos e garantias fundamentais - que por sua vez implicam na efetivação da dignidade da pessoa humana.

A par disso, pode-se afirmar que a efetivação da dignidade humana nas relações contratuais empresariais ocorre nos seguintes aspectos das negociações: (i) quando as partes exigem uma da outra que sejam adotadas práticas de não discriminação negativa e limitativas para acesso ou manutenção ao emprego; (ii) quando mutuamente se obrigam a adotar políticas de respeito às diferenças e de inclusão social de pessoas portadoras de necessidades especiais; (iii) quando se comprometem a cumprir com as determinações legais das normas de Segurança e Medicina no Trabalho; (iv) quando cumprem com suas obrigações trabalhistas; (v) quando pactuam não contratar ou permitir que seus terceirizados/quarteirizados contratem mão de obra que envolva exploração de trabalho escravo, forçado ou infantil; (vi) quando contratam exigindo que a outra parte da relação se comprometa a não empregar menores de dezesseis anos, salvo na condição de aprendiz conforme prevê a Lei no 10.097 , de 19 de dezembro de 
2000 e a Consolidação das Leis do Trabalho (CLT); (vii) quando se observa a legislação pátria para empregar adolescente menores de dezoito anos com vistas a coibir prestação de serviços em locais prejudiciais à sua formação, perigosos ou insalubres, e até mesmo trabalho noturno.

Por mais que se trate apenas de um rol exemplificativo, exigem-se muitas ações positivas da outra parte envolvida na relação, para que a dignidade da pessoa humana seja efetivamente resguardada, e para tanto, um processo de due diligence bem acertado e sensível às causas humanas, faz-se necessário.

Para isso, a recomendação é que os levantamentos, pesquisas, análises, que compõem o processo de due diligence sejam realizadas antes da conclusão de uma transação comercial, para que os resultados possam auxiliar na elaboração, inclusive, de novas cláusulas contratuais, se for o caso. O processo realizado anteriormente à conclusão da transação facilita ainda, para que o contratante adote uma postura adequada perante a sociedade preservando a sua imagem. Ainda, um processo de due diligence poderá ser mantido durante uma contratação, e ocorre por exemplo, quando a empresa contratante solicita certidões de regularidade à empresa contratada durante a vigência do negócio jurídico, ou mais que isso, quando ambas as partes autorizam a realização de auditorias a fim de certificar-se acerca das práticas adotadas sob pena de suspensão de alguma das condições previamente negociadas.

Quando se aplica a devida diligência para não admitir contratações com quem não está comprometido com a efetivação da dignidade humana, e consequentemente pactuam-se cláusulas e condições que elevam o compromisso do contratante e das demais partes relacionadas/interessadas - stakholders - com os fundamentos, objetivos e princípios constitucionalmente dispostos, o mercado está assumindo um compromisso com a erradicação da violação aos direitos dos menores, aos direitos dos grupos vulneráveis, bem como aos direitos sociais.

Por conseguinte, ao se tratar da dignidade humana e sua relação com o direito ao trabalho, é importante destacar que este, quando exercido decentemente, além de garantir a qualidade de vida do trabalhador, também promove o desenvolvimento econômico e sustentável (NOSCHANG; DARCANCHY; RIBEIRO, 2019, p. 221), e por seu turno, o trabalho escravo ou análogo ao de escravo fere diretamente a dignidade humana, e não significa apenas aquele exercido sem o exercício da liberdade física, senão veja-se:

Atualmente, quando as condições de trabalho não estão ornadas pela dignidade que deve imantar as diversas várzeas sociais que atingem o homem, quando ele se sente ferido em sua liberdade, quando, tanto física como moralmente se vê afligido por uma condição que o submete a uma situação que foge da linha do digno, quando a ele são 
impostas condições de trabalho, alimentação e higiene inadequadas, está-se submetendo o homem à condição de escravidão. (STAFFEN; BLAU, 2015, p. 307).

Dessa forma, tão desumano quanto submeter alguém a condições de discriminação ou violação de direitos mínimos é contratar alguém por menor custo, ou em razão de imprudência sem uma devida diligência que efetive a dignidade humana, mas também que contribua para a promoção de um desenvolvimento pleno, de uma nação próspera e comprometida com os mandamentos constitucionais.

Adentrando-se para o campo da Responsabilidade Social Empresarial (RSE), pode-se dizer que os processos de due diligence aplicados aos contratos empresariais podem auxiliar as empresas na promoção e efetivação da cidadania. Isso porque, segundo o Instituto Ethos (2007, p. 5), a RSE “é definida pela relação que a empresa estabelece com todos os seus públicos (stakholders) no curto e no longo prazo". E ainda, abrange temas das mais diversas áreas, como códigos de ética, práticas de boa governança, gestão e prevenção de riscos, mecanismos de anticorrupção, compromissos públicos e com a cadeia de fornecedores, diversidades, dentre outros. (ETHOS, 2007, p. 7).

O IBGC (2015, p. 13), ao publicar a quinta edição do Código de Melhores Práticas de Governança Corporativa, também explicitou a importância da ética nos negócios e ampliou a visão sobre as diversas partes relacionadas - stakholders. E, neste sentido, um processo de due diligence aplicado a terceirizados, fornecedores, poderá além de contribuir para mitigação de riscos, auxiliar ainda, na implantação de práticas adequadas de responsabilização socioambiental, trabalhista, tributária, dentre outras, e consequentemente promover a responsabilidade social.

Nesta seara, a autora Adriana Gomes de Souza (2011, p. 17), descreve que a responsabilidade social "engloba gestão, pois envolve a condução dos negócios da empresa e toda a cadeia que a circunda, preocupando-se com um público que está relacionado a todas as partes interessadas". E, da mesma forma a professora Viviane Knoerr em coautoria com Ana Cecília Parodi (2013, p. 23-24), explicam que “A Responsabilidade Social aplicada às relações negociais é uma diretriz de gestão empresarial" e mais, "Responsabilidade social é um modo de gestão para as empresas, modo de vida para os cidadãos". Por se tratar de gestão, pode-se entender que estão abarcados todos os negócios da empresa, inclusive os contratos. Assim, a gestão e prevenção de riscos através de um efetivo processo de due diligence, acaba profissionalizando os negócios de quem contrata, mas além disso, exige das partes relacionadas a adoção de práticas e medidas adequadas, socialmente responsáveis e comprometidas com a efetivação da dignidade da pessoa humana. 
É oportuno lembrar ainda, que quando se tratam de contratações com o Poder Público, a Lei de Licitações - Lei 8.666 de 1993 - traz algumas exigências com relação as regularidades trabalhistas, dentre outras, na fase de habilitação. Isso estipula à empresa licitante o dever de manter suas obrigações em dia, e ainda, diminui riscos de inexecução de contratos administrativos. (SATO, 2013, p. 1). Mas, considerando o cenário político brasileiro, os autores Silvia Regina Souza, Sandra Maciel Lima e André Lipp Pinto Basto Lupi (2018, p. 19-20), trouxeram uma moderna provocação acerca da aplicação do Compliance na Administração Pública, como forma de combate à corrupção, e também como modelo para iniciação de discussões acerca de padrões transparentes, éticos e legais, que por sua vez, também abarcam a responsabilidade social.

Percebe-se assim, que muitos assuntos percorrem em todos os ramos da sociedade, porque imprescindíveis à perfectibilização dos princípios fundamentais. Veja-se que o processo de due diligence em contratos começa a se tornar interconectado com a responsabilidade social, e acaba por ditar novos rumos para o desenvolvimento humano. O objetivo da responsabilidade social empresarial é que com a adoção de medidas e/ou comportamentos mais conscientes, as empresas, verdadeiros atores sociais, melhorem o cenário socioeconômico do país, e assim se forme uma sociedade mais justa e solidária. (CANDIDO; GADELHA; MAIA, 2017, p. 16).

Assim, com base nestas concepções verifica-se que a aplicação do processo de due diligence aos contratos empresarias, mostra-se como ferramenta adequada para efetivação da dignidade da pessoa humana e promoção da responsabilidade social empresarial, mas mais que isso, pode implicar inclusive adentrar-se para níveis de excelência no processo de governança corporativa.

\section{MECANISMOS IMPULSIONADORES DE TRANSFORMAÇÃO SOCIAL PARA EFETIVA APLICAÇÃO DO DUE DILIGENCE CONTRATUAL NO CENÁRIO BRASILEIRO}

Quando se trata de efetivação da dignidade da pessoa humana e promoção da responsabilidade social empresarial através da devida diligência nas contratações empresariais, há que se lembrar quais são as recomendações que fazem este processo se tornar efetivo, ou seja, quais seriam os impulsionadores para que o due diligence definitivamente aconteça e posteriormente a isso, seja o alicerce para se contratar ou não com determinada empresa.

ROSO (2012) bem alertou para o impacto da due diligence na concretização dos preceitos garantistas da constituição: 
Não se trata apenas de dizer que a auditoria jurídica é mais do que necessária. Tratase de afirmar, ainda, que a responsabilidade de um auditor jurídico é maior do que seu assemelhado contábil, por exemplo. Especialmente tendo em conta que sempre podem surgir conflitos interpretativos, quando se tratam de direitos fundamentais, por terem sido positivados através de enunciados genéricos. O auditor jurídico, então, interpreta a Constituição e colabora para a manutenção do equilíbrio democrático (e isso o Conselho Federal da OAB ainda não quis aceitar: não lhe chegou atingir a metanoia). (..)

As práticas de uma empresa, contudo, não repercutem apenas internamente. Podem ter grandes e graves efeitos em relação à sociedade em geral. Assim, podemos imaginar outro exemplo, em que as práticas de uma empresa (pública ou privada - e essa questão é especialmente importante atualmente, com o incremento da exploração petrolífera no País) repercutam no meio ambiente, colocando em risco a saúde, garantida no art. 6. ${ }^{\circ}$ da CF/1988 (LGL\198813), de todos os indivíduos que habitem, trabalhem, ou simplesmente circulem pela área afetada, sem esquecer as consequências ambientais, quase sempre irreparáveis.

Para facilitar este processo, o Ministério do Trabalho e Emprego criou em 2004, através da Portaria de número 540 - hoje Portaria Interministerial no 04 de 11/05/2016 - o Cadastro de Empregadores que tenham submetido trabalhadores a condições análogas à de escravo, popularmente conhecida como "lista suja”. Este castro é atualizado semestralmente, e após a inclusão dos dados do empregador nesta lista ocorre uma Inspeção do Trabalho pelo período de dois anos, sendo que, em não ocorrendo reincidência e expirado este prazo de período de inspeção, os dados do infrator são excluídos do Cadastro. (BRASIL, 2016).

Sob este aspecto, considera-se que a inserção dos dados dos empregadores que exploram mão de obra escrava na "lista suja" traz algumas consequências práticas imediatas, dentre elas o risco de imagem dada a visibilidade alcançada à sociedade, a proibição de contratação de empréstimos com bancos públicos e o isolamento econômico com relação a outras empresas que tenham aderido ao Pacto Nacional pela Erradicação do Trabalho Escravo. (PEREIRA, 2015, p. 284).

Além disso, o Banco Central do Brasil publicou através da Resolução 3.876 de 2010 do Conselho Monetário Nacional (CMN), a vedação para qualquer instituição que integre o Sistema Financeiro Nacional (SFN) contratar ou renovar operação de crédito rural a quem estiver inscrito no Cadastro de Empregadores que mantiveram trabalhadores em condições análogas de escravo. (BACEN, 2010). Esta Resolução atinge, portanto, todas as instituições financeiras, e não apenas aquelas dotadas de caráter público, o que tem provocado todos os

\footnotetext{
${ }^{5}$ A Portaria 540 foi revogada pela Portaria Interministerial no 2 de 12/05/2011, sendo que na sequencia ocorreram novas atualizações. A Portaria de 2011 foi revogada pela Portaria $\mathrm{n}^{\mathrm{o}} 2$ de 31.03.2015; que por sinal fora revogada pela Postaria vigente a de $n^{\circ} 4$ de 11/05/2016. Em 2017, a Portaria $n^{\circ} 4$ de 2016 foi alterada pela Portaria MTB $n^{\circ}$ 1.129 de 13/10/2017, mas acabou sendo alterada novamente pela $n^{\circ} 1.293$ de 28/12/2017, e aquela de $n^{\circ} 1.129$ revogada pela Portaria SEPRT no 1.417 de 19/12/2019. Em suma, a vigência atual é da Portaria Interministerial MTPS/MMIRDH n ${ }^{\circ} 4$ de 11/05/2016, com suas alterações posteriores.
} 
integrantes do SFN a tomarem mais atenção com suas políticas de sustentabilidade e responsabilidade socioambiental.

Recentemente, uma Instituição Financeira foi condenada em sede de Ação Civil Pública proposta pelo Ministério Público do Trabalho - decisão de primeiro grau da qual ainda cabe recurso - porque o Juízo de uma Vara do Trabalho compreendeu que houve descumprimento da Resolução 3.876/2010 do Conselho Monetário Nacional naquilo que tange a renovação de operação de crédito com pessoa física integrante da conhecida "lista suja". Embora a Instituição tenha apresentado defesa no sentido de que não houve nova concessão de crédito, mas apenas renegociação de operação concedida anteriormente à Resolução 3.876 foi condenada ao pagamento de dano moral coletivo, com reversão do valor ao Fundo de Amparo ao Trabalhador, bem como, de abster-se de contratar ou renovar novas operações, sob pena de novas multas por cada operação. (MARANHÃO, 2019).

O que não se pode olvidar também, é que o Brasil é signatário da Convenção número 29 da Organização Internacional do Trabalho (OIT), bem como, manifestou adesão Convenção de número 105 da mesma agência das Nações Unidas que tratam acerca do trabalho forçado ou obrigatório, e das medidas relativas para sua supressão, o que coloca o país como referência internacional de proteção aos direitos humanos e do trabalho, quando conjugado com a legislação pátria. (NOSCHANG; DARCANCHY; RIBEIRO, 2019, p. 228). Mesmo assim, o país já foi condenado no âmbito internacional por haver trabalhadores submetidos a condições de escravagismo ${ }^{6}$, e apesar de todo arcabouço legislativo nacional, depara-se com trabalho em condições análogas a de escravo com preponderância no ambiente rural7

A Administração Pública, por sua vez, também tem se demonstrado preocupada com alguns atos praticados pela iniciativa privada em contratações com o Poder Público, e, por isso, os mecanismos de devida diligência antes e durante a relação contratual também ganharam força, principalmente com a edição da Lei 12.486 de 2013. Amplamente conhecida como Lei Anticorrupção, este normativo dispõe sobre a responsabilização administrativa e civil de pessoas jurídicas pela prática de atos contra a administração pública, nacional ou estrangeira, e por isso, a adoção do processo de due diligence tornou-se necessário para levantamentos de passivo corruptivo e desvios de conduta, uma vez que, o referido diploma legal em seu artigo $2^{\circ}$, caput, prevê que: “As pessoas jurídicas serão responsabilizadas objetivamente, nos âmbitos

\footnotetext{
${ }^{6}$ Caso "Zé Pereira" revelou que o trabalhador rural José Pereira Ferreira, trabalhava em condições análogas à de escravo.

${ }^{7}$ Dados do Painel de Informações e Estatísticas da Inspeção do Trabalho no Brasil.
} 
administrativo e civil, pelos atos lesivos previstos nesta Lei praticados em seu interesse ou benefício, exclusivo ou não", e mais adiante, em seu artigo $4^{\circ}$, caput dispõe que "Subsiste a responsabilidade da pessoa jurídica na hipótese de alteração contratual, transformação, incorporação, fusão ou cisão societária.”. (BRASIL, 2013).

Da mesma forma, o Decreto 8.420 de 2015 que regulamenta a Lei Anticorrupção trouxe a criação do Cadastro Nacional de Empresas Inidôneas e Suspensas - CEIS - que implica em restrição ao direito de participar de licitações ou de celebrar contrato com a Administração Pública em razão de impedimento, suspensão ou declaração de inidoneidade. ${ }^{8}$ Este Cadastro Nacional se refere basicamente a disposições da Lei de Licitações (8.666), naquilo que tange a inexecução de contrato; à Lei do Pregão Eletrônico quando a empresa deixa de celebrar contrato ou deixa de entregar documentação válida no prazo da contratação; em razão de descumprimento da Lei de Acesso da Informação; e ainda, em razão de sanções administrativas impostas pela Lei de Regime Diferenciado de Contratações Públicas - RDC. Note-se, no entanto, que não há obrigação à observância do Cadastro de Empregadores que tenham submetido trabalhadores a condições análogas à de escravo do Ministério do Trabalho, porque não se encontra na legislação federal, algum dispositivo neste sentido.

Todavia, a Lei de Licitações, conforme já mencionado no capítulo anterior trata da exigência da comprovação de regularidade fiscal e trabalhista para contratação com a Administração pública, mas não abarca o cadastro na "lista suja", que se tratam de questões distintas, haja vista que, poderá determinada empresa estar cumprindo regularmente com suas obrigações trabalhistas, mas mesmo assim, ainda estar cumprindo a sua "quarentena" de dois anos naquela lista que é mais grave.

O Estado do Rio Grande do Sul, por seu turno, possui uma Lei Estadual - 11.389, de 25 de novembro de 1999, alterada pela Lei 14.657 de 2014 - que instituiu o Cadastro de Fornecedores Impedidos de Licitar e Contratar com a Administração Pública Estadual, e dentre eles faz trata como impedidas às empresas que tenham sido condenadas definitivamente por crime de redução à condição análoga à de escravo, pelo período de oito anos após a data de condenação. Mas, note-se que apenas em caso de apuração de crime, e após a ocorrência do trânsito em julgado.

De todo modo, a lei não conseguirá salvaguardar todas as hipóteses de observações necessárias para garantia da dignidade humana ou promoção da responsabilidade social, mas a “investigação" por parte de toda a classe empresarial, antes e durante as contratações, torna-se

\footnotetext{
${ }^{8}$ Artigo 43 do Decreto 8.420.
} 
primordial para que os fundamentos, objetivos e princípios constitucionais possam ser resguardados. A geração de riqueza tende a assumir novos objetivos, e para que as empresas se mantenham eficientes e respeitadas no mercado, novas práticas se fazem necessárias, uma vez que, a responsabilidade social começa a cumprir com a sua função de formação ético de todos os stakholders, ou seja, empregados, familiares, fornecedores e parceiros. (SOUZA, 2011, p. 17).

No entanto, apesar de a legislação não salvaguardar todos os mecanismos necessários para uma efetiva aplicação da devida diligência contratual no cenário brasileiro, denota-se que Cadastro de Empregadores que tenham submetido trabalhadores a condições análogas à de escravo - "Lista Suja", a Resolução 3.876 do CMN e o Pacto Nacional pela Erradicação do Trabalho Escravo despontam como mecanismos impulsionadores para um processo sério de due diligence, e consequentemente de efetivação da dignidade da pessoa humana e promoção da responsabilidade social empresarial. Do mesmo modo, o Cadastro Nacional de Empresas Inidôneas e Suspensas constituído em razão da regulamentação da Lei Anticorrupção manifesta-se como um mecanismo apropriado de due diligence no âmbito das contratações com a Administração Pública, e também serve como instrumento de transformação social, pois implica em divulgação pública de impedimento, suspensão e declaração de inidoneidade para todos os Entes da Federação.

Para finalizar, cumpre destacar ainda que nesta busca pela responsabilidade social e concretização da dignidade humana, faz-se necessário que as organizações estabeleçam um planejamento e persigam indicadores voltados a esta prática, mas mais que isso, que neste caminho procurem conjuntamente com o governo e demais instituições civis, "reduzir os índices de marginalização, de forma a restabelecer a dignidade da pessoa humana a quem não se perceba detentor deste direito" (BERTONCINI; MARKOVICZ, 2012, p. 401), porque este é o verdadeiro mecanismo de transformação social que precisa ser perseguido.

\section{CONSIDERAÇÕES FINAIS}

Ao se tratar dos mecanismos impulsionadores dos processos de due diligence nas contratações empresarias que recomendam a efetivação da dignidade da pessoa humana e promoção da responsabilidade social está se assumindo que a devida diligência deixa de assumir um papel apenas de análise econômico-financeira, e exerce função coerente com as expectativas de desenvolvimento nacional de forma ética e sustentável, com observância dos 
preceitos constitucionais, bem como das Convenções Internacionais a que o Brasil tenha aderido.

Negociar e contratar é essencial para manutenção da atividade econômica, e consequentemente para geração de riquezas, emprego e renda, distribuição de saúde e educação de qualidade, mas exige-se das empresas que cada vez mais sejam adotadas práticas de gestão voltadas para a responsabilidade social e efetivação da dignidade humana, e a aplicação da devida diligência prévia e permanente às negociações/contratações é uma recomendação que auxilia na formação de uma sociedade mais justa e solidária, tão almejada por todos.

Hodiernamente, o Brasil já possui mecanismos de due diligence impulsionadores à efetivação da dignidade humana e responsabilização social no âmbito das contratações empresariais, e dentre eles, estão contemplados a "Lista Suja" do Ministério de Trabalho e Emprego - que trata do cadastro de empregadores que que tenham submetido trabalhadores a condições análogas à de escravo - a Resolução 3.876 do CMN que proíbe a concessão ou renovação de crédito rural a empresas constantes nesta "lista suja", o Pacto Nacional pela Erradicação do Trabalho Escravo que permite que as empresas de forma livre e deliberada manifestem a sua adesão, bem como, o Cadastro Nacional de Empresas Inidôneas e Suspensas da Lei Anticorrupção, sendo que este último trata apenas das contratações com a Administração Pública e não afeta diretamente os direitos e garantias fundamentais, mas auxilia na concretização do interesse público.

Logo, é possível compreender que o Brasil possui mecanismos eficazes para a concreta realização de um processo de due diligence, com vistas à efetivação da dignidade humana e promoção da responsabilidade social, basta o Estado naquilo que lhe cabe, e o particular em cada contratação, exigir dos seus terceirizados, e até mesmo quarteirizados a adoção desta postura de observância mínima destes mecanismos.

\section{REFERÊNCIAS}

ALVAREZ, María I. T.; BERMUDEZ, Alvaro V.; FLORES, Martín Z.; FIESTAS, Carolina, S.; NAJAR, Alejandra, T. M.; STUCCHI, Carlo S.; URETA, Marianne, F.; VARGAS, Sérgio A.; YASUMOTO Teresa T. La due diligence legal. Themis - Revista de Derecho, Peru, $n^{\circ} 59$, p. 213-227. Disponível em: <http://revistas.pucp.edu.pe/index.php/themis/article/viewFile/9105/9516 >. Acesso em: 19 fev. 2020.

ALVES, Edmilson P.; HARET, Florence C.; SILVEIRA, Daniel B. Governança corporativa e soberania popular: mecanismo de controle do poder do estado na sociedade e economia. Revista Economic Analysis Of Law Review, Brasília, v.6, n² 2, p. 333-355, 2015. Disponível 
em: $\quad<$ https://search.proquest.com/openview/0d27ffb8581b6afbda5082a47a3d6fda/1?pqorigsite $=$ gscholar \&cbl=1226335>. Acesso em: 16 fev. 2020.

ARRUDA, Pablo Gonçalves. Governança Corporativa: origem, significado e importância. Fundação Getúlio Vargas: LLM em Direito Empresarial, Direito Societário II, Rio de Janeiro, 2017, p. 61.

BAM, W.G.; BHAGWAN, V.; GROBBELAAR, S.S. A systematic review of the due diligence stage of mergers and acquisitions: towards a conceptual framework. South African Journal of Industrial Engineering, África do Sul, v.29, $\mathrm{n}^{\mathrm{o}}$ 3, p. 217-234, 2018. Disponível em: <http://www.scielo.org.za/pdf/sajie/v29n3/18.pdf>. Acesso em: 20 fev. 2020.

BARBERO, E. R.; BURKE, J.; HASHIMOTO, M.; SALATI, G. H. Mitigação de riscos em investimento-anjo: modelo conceitual e evidências qualitativas. Revista Gestão e Planejamento, Salvador, v.17, $\mathrm{n}^{\mathrm{o}}$ 2, p. 348-366, 2016. Disponível em: < https://www.researchgate.net/profile/Marcos_Hashimoto/publication/309881588_Forum_Te matico_-_MITIGACAO_DE_RISCOS_EM_INVESTIMENTO-

ANJO_MODELO_CONCEITUAL_E_EVIDENCIAS_QUALITATIVAS/links/583aedf708a e3a74b4a053e8/Forum-Tematico-MITIGACAO-DE-RISCOS-EM-INVESTIMENTO-ANJOMODELO-CONCEITUAL-E-EVIDENCIAS-QUALITATIVAS.pdf>. Acesso em: 22 fev. 2020.

BATALHA, Sara C. C. A responsabilidade pré-contratual por violação dos deveres da boafé: a importância de uma due diligence. $126 \mathrm{f}$. Dissertação

(Mestrado Profissionalizante em Direito e Economia) - Faculdade de Direito - Universidade de Lisboa, Lisboa, 2016.

BERTONCINI, Mateus Eduardo Siqueira Nunes; MARKOVICZ, Silvia. O princípio da dignidade da pessoa humana e a responsabilidade social das empresas privadas. Revista Jurídica, Curitiba, v. 2, $\mathrm{n}^{\mathrm{o}}$. 29, p. 375-405, 2012. Disponível em: $<$ http://revista.unicuritiba.edu.br/index.php/RevJur/article/view/529>. Acesso em: 22 fev. 2020.

BLOK, Marcella. Reestruturações societárias: uma boa solução para empresas em crise?

Revista dos Tribunais, v. 945, p. $105-155$, Jul/2014.

BRASIL. Constituição (1988). Constituição da República Federativa do Brasil de 1988, de 05 de outubro de 1988. Brasília, 1988. Disponível em: <http://www.planalto.gov.br/ccivil_03/constituicao/constituicao.htm>. Acesso em: 22 fev. 2020.

BRASIL. Lei $\mathrm{n}^{\circ}$ 8.666, de 21 de junho de 1993. Regulamenta o art. 37, inciso XXI, da Constituição Federal, institui normas para licitações e contratos da Administração Pública e dá outras providências. Diário Oficial [da] República Federativa do Brasil, Brasília, DF, 21 jun. 1993. Disponível em: < http://www.planalto.gov.br/ccivil_03/leis/18666cons.htm>. Acesso em: 22 fev. 2020.

BRASIL. Lei $\mathrm{n}^{\circ} 10.303$, de 31 de outubro de 2001. Altera e acrescenta dispositivos na Lei $\mathrm{n}^{\circ}$ 6.404, de 15 de dezembro de 1976, que dispõe sobre as Sociedades por Ações, e na Lei $\mathrm{n}^{\circ}$ 6.385, de 7 de dezembro de 1976, que dispõe sobre o mercado de valores mobiliários e cria a Comissão 
de Valores Mobiliários. Diário Oficial [da] República Federativa do Brasil, Brasília, DF, 31 out. 2001. Disponível em: <http://www.planalto.gov.br/ccivil_03/leis/leis_2001/110303.htm>. Acesso em: 23 fev. 2020.

BRASIL. Banco Central do Brasil. Resolução no 3.876 de 2010. Veda a concessão de crédito rural para pessoas físicas ou jurídicas que estão inscritas no Cadastro de Empregadores que mantiveram trabalhadores em condições análogas à de escravo instituído pelo Ministério do Trabalho e Emprego. Diário Oficial [da] União, Brasília, DF, 22 jun. 2010. Disponível em: <https://www.bcb.gov.br/pre/normativos/res/2010/pdf/res_3876_v1_O.pdf>. Acesso em: 23 fev. 2020.

BRASIL. Lei $\mathrm{n}^{\mathrm{o}} 12.846$, de 01 de agosto de 2013. Dispõe sobre a responsabilização administrativa e civil de pessoas jurídicas pela prática de atos contra a administração pública, nacional ou estrangeira, e dá outras providências. Diário Oficial [da] República Federativa do Brasil, Brasília, DF, 02 ago. 2013. Disponível em: <http://www.planalto.gov.br/ccivil_03/_Ato2011-2014/2013/Lei/L12846.htm>. Acesso em: 24 fev. 2020.

BRASIL. Decreto $\mathrm{n}^{\circ} 8.420$, de 18 de março de 2015. Regulamenta a Lei $\mathrm{n}^{\mathrm{o}} 12.846$, de $1^{\circ}$ de agosto de 2013, que dispõe sobre a responsabilização administrativa de pessoas jurídicas pela prática de atos contra a administração pública, nacional ou estrangeira e dá outras providências. Diário Oficial [da] República Federativa do Brasil, Brasília, DF, 19 mar. 2015. Disponível em: < http://www.planalto.gov.br/ccivil_03/_Ato2015-2018/2015/Decreto/D8420.htm>. Acesso em: 24 fev. 2020.

BRASIL. Portaria Interministerial MTPS/MMIRDH n ${ }^{\circ} 4$ de 11/05/2016. Dispõe sobre as regras relativas ao Cadastro de Empregadores que tenham submetido trabalhadores a condições análogas à de escravo. Diário Oficial [da] União, Brasília, DF, 13 maio 2016. Disponível em: <https://www.legisweb.com.br/legislacao/?id=320458>. Acesso em: 23 fev. 2020.

BRASIL. Superior Tribunal de Justiça. Recurso Especial nº 1.789.554, Decisão Monocrática do Ministro Herman Benjamin, Brasília, DF, 07 de fevereiro de 2019. Superior Tribunal de Justiça.

Disponível

em: <https://ww2.stj.jus.br/processo/revista/documento/mediado/?componente=MON\&sequencial $=92070363 \&$ num_registro=201803446837\&data=20190307>. Acesso em $21 \mathrm{fev} .2020$.

CANDIDO, Gesinaldo A.; GADELHA, Maria A.; MAIA, Antônio A. M. Ações de responsabilidade social empresarial a partir do modelo tridimensional performance social: o caso de uma indústria do setor alimentício do Ceará. 1.ed. Ampere: FAMPER, 2017. E-book.

DUEÑAS, Jennyfer L. P. Due diligence: un paso previo e indispensable en toda negociación. 21 f. Ensayo (Programa Especialización En Gerencia De Comercio Internacional) - Universidad Militar Nueva Granada, Bogotá, 2014.

ETHOS, Instituto. Conceitos básicos e indicadores de responsabilidade social empresarial. 5. ed. São Paulo: Instituto Ethos, 2007. Disponível em: <https://www.ethos.org.br/wpcontent/uploads/2014/05/Conc_Bas_e_Indic_de_Respon_Soc_Empres_5edi.pdf $>$. Acesso em: 22 fev. 2020. 
GUSMÃO, Mônica. Lições de Direito Empresarial. 12. ed. Rio de Janeiro: Forense, 2015.

IBGC. Instituto Brasileiro De Governança Corporativa. Código das Melhores Práticas de Governança Corporativa. 1. ed. São Paulo: IBGC, 1999. Disponível em: $<$ https://conhecimento.ibgc.org.br/Lists/Publicacoes/Attachments/21135/IBGC_1999_Codigo ...fol.pdf.pdf $>$. Acesso em: 21 fev. 2020.

IBGC. Código das Melhores Práticas de Governança Corporativa. 5. ed. São Paulo: IBGC, 2015. Disponível em: $<$ https://conhecimento.ibgc.org.br/Lists/Publicacoes/Attachments/21138/PublicacaoIBGCCodigo-CodigodasMelhoresPraticasdeGC-5aEdicao.pdf >. Acesso em: 21 fev. 2020.

KNOERR, Viviane C. S.; PARODI, Ana C. Responsabilidade jurídica social empresarial (RJSE): ética empresarial e deontologia, no diálogo entre as normas de mercado e as normas jurídicas. Sustentabilidade econômica e social em face à ética e ao direito. Recurso eletrônico on-line. Organização: CONPEDI/ UNICURITIBA, Florianópolis: FUNJAB, 2013. Disponível em: < http://www.publicadireito.com.br/artigos/?cod=ee07c6fb926a29e3>. Acesso em: 21 fev. 2020.

KUZNECOV, Natália. Cláusulas contratuais para mitigação de riscos de Compliance. $55 \mathrm{f}$. Monografia (Pós-graduação Lato Sensu em Direito dos Contratos - LLM) - Insper, São Paulo, 2017.

LIMA, Sandra M.; LUPI, André L. P. B.; SOUZA, Silvia R. Aplicabilidade do Compliance na administração pública em face ao momento político atual brasileiro. Percurso: Sociedade, Natureza e Cultura, Curitiba, v.1, $\mathrm{n}^{\mathrm{o}}$ 24, p. 1-22, 2018. Disponível em; < http://revista.unicuritiba.edu.br/index.php/percurso/article/view/3274>. Acesso em: 22 fev. 2020.

LOBO, Jorge. Princípios de Governança Corporativa. Revista da EMERJ, Rio de Janeiro, v.10, nº 37, p. 198-220, 2007.

LONDOÑO, Iván D. R. Due Diligence Financiera, una forma para garantizar la toma eficiente de decisiones en la adquisición de empresas. El Cuaderno - Escuela de Ciencias Estratégicas, Colômbia, v.2, $\mathrm{n}^{\mathrm{o}}$ 4, p. 263-278, 2008. Disponível em: <https://scholar.google.com.br/scholar>. Acesso em: 18 fev. 2020.

MARANHÃO. Justiça do Trabalho. Ação Civil Pública nº 0018256-81.2017.5.16.0015, Sentença de Primeiro Grau, São Luís, MA, 08 de julho de 2019. Tribunal Regional do Trabalho da $16^{\text {a }}$ Região. Disponível em: <https://pje.trt16.jus.br/consultaprocessual/detalheprocesso/00182568120175160015>. Acesso em 24 fev. 2020.

NOSCHANG, Patrícia Grazziotin; DARCANCHY, Mara; RIBEIRO, Sirlene Elias. O controle de convencionalidade no Direito Internacional do Trabalho como garantia do trabalho decente no Brasil: o caso dos trabalhadores da Fazenda Brasil Verde. In: ROCHA, Débora Cristina de Castro Da; TRIPPIA, Luciane Maria. (Coord). CHWEIH, Samira Zeinedin; CRISTO, Viviane Duarte Couto de. (Org). Direito sob a perspectiva feminina. 1.ed. Curitiba: Jiruá, 2019. p.214229. 
PANOSSO, Morgana S. Responsabilidade pré-contratual por omissão dolosa na realização da due diligence societária. 58 f. Monografia (Graduação em Direito) - UFRGS, Porto Alegre, 2013.

PEREIRA, Maria da Conceição Maia. A Lista Suja como instrumento eficiente para reprimir a exploração de mão de obra em condições semelhantes à escravidão. Revista do Direito do Trabalho e Meio Ambiente do Trabalho, Minas Gerais, v. 1, n. 2, p. 273-294, 2015. Disponível em:< https://indexlaw.org/index.php/revistadtmat/article/view/351>. Acesso em: 23 fev. 2020.

PIOVESAN, Flávia. Direitos Humanos e o Direito Constitucional Internacional. 18. ed. São Paulo: Saraiva, 2018.

RAUPP, Fabiano M; WARKEN, Ricardo M. Utilização da due diligence em processos de fusão e aquisição. Pensar Contábil, Rio de Janeiro, v.11, no 45, p. 34-40, 2009. Disponível em: < http://www.atena.org.br/revista/ojs-2.2.3-

06/index.php/pensarcontabil/article/viewFile/136/137>. Acesso em: 17 fev. 2020.

ROCHA, Dinir Salvador Rios da. Visão Geral de Due Diligence: Breves Aspectos Teóricos e Práticos. In: QUATRINI, Larissa; ROCHA, Dinir Salvador Rios da (Coord). Direito Societário - Fusões, Aquisições, Reorganizações Societárias e Due Diligence. 1.ed. São Paulo: Saraiva, 2012. E-book.

RIZZARDO, Arnaldo. Contratos. 14. ed. Rio de Janeiro: Forense, 2014.

ROSENBLOOM, Arthur H. Due Diligence in the Global Economy. In: ROSENBLOOM, Arthur H. (Coord). Due Diligence for Global Deal Making: The Definitive Guide to CrossBorder Mergers and Acquisitions, Joint Ventures, Financings, and Strategic Alliances. 1.ed. Nova York: Bloomberg Press, 2002. E-book.

ROSO, Jaime. Auditoria Jurídica para a Sociedade Líquida Brasileira. Revista do Instituto dos Advogados de São Paulo, v. 29, p. 343 - 375, Jan - Jun / 2012.

SATO, Guilherme P. A regularidade fiscal na licitação como meio de proteção ao interesse público. Revista da AGU, Brasília, ano 12, n ${ }^{\mathbf{0}}$ 37, jul./set. 2013. Disponível em: <https://seer.agu.gov.br/index.php/AGU/issue/view/4>. Acesso em 22 fev. 2020.

SILVA, Rogério Luiz Nery da; MASSON, Daiane Garcia. Direitos sociais e a dignidade humana: reflexões a partir do conceito de mínimo existencial. In: ALEXY, Robert; BAEZ, Narciso Leandro Xavier; SILVA, Rogério Luiz Nery da. (Coord). Dignidade Humana, Direitos Sociais e Não-Positivismo Inclusivo. 1.ed. Florianópolis: Qualis, 2015. p.179-214.

SOUZA, Adriana Gomes de. Responsabilidade Social Empresarial: Ética ou Marketing? 1. ed. Rio de Janeiro: Synergia, 2011. E-book.

STAFFEN, Marcio Ricardo; BLAU, Fernanda Maiara Staehr. O combate dos meios de escravidão pelo direito transnacional. Revista Jurídica, Curitiba, v. 2, no. 39, p. 300-320, 2015. Disponível em: <http://revista.unicuritiba.edu.br/index.php/RevJur/article/view/1535>. Acesso em: 22 fev. 2020. 